\title{
Erratum to: MDCT findings in neuroendocrine carcinoma of the gallbladder: case report
}

\author{
F. Obuz, ${ }^{1}$ C. Altay, ${ }^{1}$ O. Sagol, ${ }^{2}$ H. Astarcioglu, ${ }^{3}$ I. Oztop, ${ }^{4}$ E. Igci ${ }^{1}$
}

${ }^{1}$ Department of Radiology, Dokuz Eylul University School of Medicine, Izmir, Turkey

${ }^{2}$ Department of Pathology, Dokuz Eylul University School of Medicine, Izmir, Turkey

${ }^{3}$ Department of Surgery, Dokuz Eylul University School of Medicine, Izmir, Turkey

${ }^{4}$ Department of Medical Oncology, Dokuz Eylul University School of Medicine, Izmir, Turkey

\section{Erratum to: Abdom Imaging (2007) 32:105-107 DOI 10.1007/s00261-006-9002-6}

This article was inadvertently published a second time under DOI: 10.1007/s00261-006-9122-z.

Official publication is under DOI: 10.1007/s00261-006-9002-6 Abdom Imaging (2007) 32:105-107.

The online version of the original article can be found under doi:10.1007/s00261-006-9002-6.

Correspondence to: F. Obuz; email: fobuz@deu.edu.tr 